\title{
Psicologia e políticas sociais: as contribuições de um programa de pós-graduação em Psicologia
}

Lenise Santana Borges. Pontifícia Universidade Católica de Goiás

Rosana Carneiro Tavares. Pontifícia Universidade Católica de Goiás

Sonia M. Gomes Sousa. Pontifícia Universidade Católica de Goiás

Vannúzia Leal Andrade Peres. Pontifícia Universidade Católica de Goiás

\section{Resumo}

Este artigo analisa a produção acadêmica sobre políticas sociais do Programa de Pós-Graduação em Psicologia da Pontifícia Universidade Católica de Goiás (PUC Goiás), no período de 2001 a 2018. O levantamento bibliográfico foi realizado por meio da Plataforma Sucupira, em que foram catalogadas 421 dissertações e 63 teses. Após o processo de seleção foram analisados 39 resumos, por meio do referencial teórico da Psicologia Crítica. Embora em número reduzido, essas dissertações e teses que dialogam com as políticas sociais refletem a expansão da pesquisa em Psicologia, como campo científico que se compromete com a transformação da realidade social. Foram eleitas duas categorias de análise desses resumos: programas, serviços, unidades e instituições públicos, e vulnerabilidades e risco social. Essas pesquisas, em sua grande maioria, oferecem subsídios para a criação e/ou aperfeiçoamento das políticas sociais no Brasil e, concomitantemente, evidenciam desafios a serem enfrentados. Palavras-chave: psicologia; políticas públicas; política social; pesquisa científica; pós-graduação.

\section{Abstract}

Psychology and social policies: contributions from a postgraduate program in Psychology. This paper looks at social policies in the Postgraduate Program in Psychology, held by Pontifícia Universidade Católica de Goiás (PUC Goiás) from 2001 to 2018. The bibliographic survey was performed using the Sucupira Database Platform, in which 421 dissertations and 63 theses were catalogued. After the selection, 39 abstracts were analyzed according to the theoretical references in Critical Psychology. Although in a reduced number, these dissertations and theses, with focus on social policies, showed the expansion of scientific production in Psychology, in order to change the social reality. In the purpose of analyzing the abstracts, two categories were chosen. The first one was related to programs, services, units and public institutions; the second category is associated to vulnerability and social risk. Most of scientific productions offered an important aid when implementing or improving social policies in Brazil, and, thus, showed the challenges to be faced.

Keywords: psychology; public policies; social policies; scientific production; postgraduation.

\section{Resumen}

Psicología y políticas sociales: las contribuciones de um programa de postgrado en Psicologia. Este artículo analiza la producción académica sobre políticas sociales del Programa de Postgrado en Psicología de la Pontifícia Universidade Católica de Goiás (PUC Goiás), en el período del 2001 al 2018. El levantamiento bibliográfico se realizó por medio de la Plataforma Sucupira, en que fueron catalogadas 421 disertaciones y 63 tesis. Después del proceso de selección se analizaron 39 resúmenes, por medio del referencial teórico de la Psicología Crítica. Pese el pequeño número, esas disertaciones y tesis que dialogan con las políticas sociales reflejan la expansión de la pesquisa en Psicología, como campo científico que se compromete con la transformación de la realidad social. Así, se eligieron dos categorías de análisis de esos resúmenes: programas, servicios, unidades y instituciones públicas, así como vulnerabilidades y riesgo social. Esas pesquisas ofrecen, en buena parte, subsidios para la creación y/o el perfeccionamiento de las políticas sociales en Brasil y, concomitantemente, evidencian los desafíos que deben enfrentarse.

Palabras clave: psicología; políticas públicas; política social; pesquisa científica; postgrado. 
Investigar a produção acadêmica em uma área específica do conhecimento pode iluminar questões relevantes da vida social em seu sentido mais amplo, expressar tensões e disputas presentes em qualquer campo de investigação e, ainda, apontar tanto os campos dominantes quanto aqueles em emergência. Com base nessa afirmação, a Pós-Graduação Stricto Sensu (PSS) é um lugar privilegiado de investigação da produção de conhecimento (dissertações e teses), por permitir a análise dos contextos de sua realização, das perspectivas em termos de conexão com os problemas sociais, bem como das demandas por suas soluções (A. L. F. Costa \& Yamamoto, 2016; Yamamoto \& Oliveira, 2010).

Além disso, a PSS tem sido reconhecida como uma das experiências mais exitosas no contexto do sistema educacional brasileiro por uma conjunção de fatores sociais, econômicos, políticos e acadêmicos (Bastos \& Godim, 2010). A despeito de sua importância, questionamentos quanto à importância de não se dissociar o desenvolvimento científico e tecnológico do desenvolvimento social começam a ter destaque.

No caso específico da articulação entre a PSS e o desenvolvimento social, uma das alternativas possíveis é o alargamento da compreensão sobre políticas sociais (A. L. F. Costa \& Yamamoto, 2016). Documentos, como o Plano Nacional de Pós-Graduação (de 2005 a 2010), o de área (2013) e do próprio Programa de Pós-Graduação Stricto Sensu em Psicologia (PSSP) (2013-2016), passam a registrar a inserção social das pesquisas científicas e suas contribuições para o desenvolvimento social. Tudo se passa em um contexto de transformações internas e externas à profissão, tais como: a presença de vertentes mais críticas da Psicologia, a emergência de políticas públicas voltadas às populações socialmente excluídas e os impactos da crise no mercado de trabalho de profissionais que atuam na clínica. Todos esses fatores indicam uma transição deste último perfil profissional para uma inserção progressiva de psicólogos nos campos do bem-estar social, principalmente nos serviços públicos (A. L. F. Costa \& Yamamoto, 2016).

Nessa direção, o presente artigo se debruça sobre as pesquisas realizadas no PSSP da Pontifícia Universidade Católica de Goiás (PUC Goiás) no período de 2001 a 2018, que têm por objeto a produção sobre políticas sociais. O PSSP de Goiás é relativamente recente: o mestrado foi criado em 1999, e o doutorado em 2006, com três linhas de pesquisa: Análise do Comportamento, Psicologia Social e do Trabalho e das Organizações, Psicopatologia Clínica e Psicologia da Saúde. Nesse período se produziram 421 dissertações e 63 teses, das quais 39 resumos constituem o corpus deste artigo.

Em razão de ser um campo em expansão, os trabaIhos selecionados nesta pesquisa têm por foco os sujeitos pertencentes a grupos considerados mais vulneráveis, interesse primordial das políticas sociais. Tais políticas se relacionam à cidadania e, consequentemente, aos direitos humanos (civis, políticos e sociais) de crianças, adolescentes, jovens, idosos, mulheres, presidiários e grupos LGBTT+ (lésbicas, gays, bissexuais, transexuais e transgêneros), entre outros que foram conquistados mediante lutas dos movimentos sociais. Em um sentido mais geral, esta pesquisa busca compreender como diferentes trabaIhos de uma mesma área de concentração (Psicologia), de diferentes linhas de pesquisa, de alguma forma, abordam o direito de cidadania de diferentes indivíduos, e como esse direito é relacionado ao dever do Estado de assegurar o atendimento às suas necessidades (direito à educação, à justiça, à assistência social e a um ambiente que possibilite um modo de vida saudável).

\section{Metodologia}

O "estado da arte", ou "estado do conhecimento", da produção acadêmica do PSSP em foco se apoiou em uma afirmação de N. S. A. Ferreira (2002), para quem as pesquisas bibliográficas "parecem trazer em comum o desafio de mapear e de discutir uma certa produção acadêmica em diferentes campos do conhecimento [...] e por realizarem uma metodologia de caráter inventariante e descritivo da produção acadêmica e científica sobre o tema" (p. 258).

Ao optar por pesquisar os resumos dos trabaIhos acadêmicos, levou-se em conta seu caráter indispensável na difusão do conhecimento, pois "informam ao leitor, de maneira rápida, sucinta e objetiva sobre o trabalho do qual se originam" (N. S. A. Ferreira, 2002, p. 268). Também Zanella e Titon (2005) utilizaram os resumos para terem acesso à produção científica da Psicologia, se bem que na área da criatividade.

A coleta das informações foi realizada no Banco de Dissertações e Teses da Plataforma Sucupira, no qual se levantaram os trabalhos acadêmicos defendidos no período de 2001 (data da primeira defesa) a 2018 (último ano com a produção completa, visto que o levantamento foi realizado nos dias 7 e 8 de fevereiro de 2019). Após a localização das dissertações (421) e teses (63), os respectivos resumos foram organizados por ano e tipo (dissertação ou tese) em um arquivo de Word, contendo o título, o nome do aluno-autor, o nome do orientador e o resumo.

Estudos de Psicologia, 24(2), abril a junho de 2019, 171-180 
O procedimento seguinte foi a leitura dos títulos e resumos para aplicação dos critérios de inclusão e exclusão. No processo de seleção dos resumos das dissertações e teses que pesquisaram temas relacionados às políticas sociais, foram utilizados os seguintes critérios de inclusão, no que tange ao título e ao resumo: 1) deveriam conter os termos "políticas públicas" ou "políticas sociais"; 2) deveriam fazer referência a instituições públicas ou ONGs, como, por exemplo, o Centro de Referência da Assistência Social (Cras), a Secretaria de Direitos Humanos da Presidência da República (SEDH/PR), o Centro de Valorização da Mulher (Cevam), a Delegacia Especial de Atendimento a Mulheres (Deam); 3) deveriam mencionar programas sociais ou políticas públicas, como, por exemplo, Help Line, Programa de Erradicação do Trabalho Infantil (Peti), Medidas Socioeducativas, Disque 100, Sistema de Garantia de Direitos, SEDH/PR.

Da mesma forma, foram excluídos os resumos cujos temas aparentemente tratavam da "questão social", mas não dialogavam com as políticas sociais ou com programas sociais, restringindo-se ao(s) sujeito(s) e ao seu entorno imediato (organização, instituição etc.).

A partir da aplicação dos critérios de inclusão e exclusão, obteve-se uma lista com os títulos e resumos selecionados nesta etapa. A eficácia desses critérios nos resumos selecionados foi então submetida à análise de cinco juízas, as quatro autoras deste artigo e uma avaliadora externa. Inicialmente todas as autoras leram as 484 produções (títulos e resumos) organizadas por ano de defesa e construíram individualmente uma lista dos resumos que seriam analisados. Essas quatro listas foram cotejadas, observando-se então 35 divergências (7,2\%), que, após discussão, foram submetidas à avaliadora externa em uma única lista com 41 possíveis resumos. Ao final da avaliação, dois trabalhos foram excluídos, o que resultou na amostra de 39 resumos.

A sistematização se deu por meio da leitura dos títulos e dos resumos à luz dos critérios estabelecidos para a definição do corpus da pesquisa. A análise foi empreendida por meio do referencial teórico da Psicologia Crítica, da produção acadêmica sobre Psicologia e políticas sociais e da bibliografia relacionada aos temas identificados.

\section{Resultados e discussão}

\section{A Psicologia em Diálogo com as Políticas Sociais \\ É sabido que as políticas sociais se concreti- zam pelo estabelecimento de estratégias do Estado}

para a resolução de problemas sociais, que advêm do modo de produção capitalista e remetem à necessidade de se compreender a "questão social", exposta na contradição entre capital e trabalho. Para Yamamoto e Oliveira (2010), "a Questão Social pode ser definida como o conjunto dos problemas políticos, sociais e econômicos postos pela emergência da classe operária no processo de constituição da sociedade capitalista" (p. 10). Dessa forma, a política social necessita ser compreendida ao longo do processo do modo de produção capitalista, no qual a classe trabalhadora enfrenta desigualdades de acesso a bens e serviços e torna-se "objeto de intervenção sistemática por parte do Estado, mas de forma fragmentária e parcializada" (Yamamoto \& Oliveira, 2010, p. 10). Isso ocorre, principalmente, porque as políticas públicas brasileiras foram constituídas historicamente com processos decisórios a partir de interesses políticos e não das necessidades da população. Essas políticas tornam-se, assim, uma estratégia de poder em que "um dos efeitos é a dominação, a disciplina e a docilização dos corpos e da vida" (Macedo \& Dimenstein, 2009, p. 294). Como exemplo, é importante mencionar a forma como o Estado tratou os problemas sociais decorrentes dos processos de sofrimento psíquico e da atenção à saúde mental - uma história não só marcada pela intervenção autoritária do Estado e pela perspectiva higienista da sociedade, mas também reprodutora da violência por meio de técnicas de disciplinamento (S. M. G. Sousa \& Tavares, 2012).

Reconhecendo esse processo de implementação de políticas sociais segmentadas, cabe destacar que a Psicologia, ao dialogar com essas políticas, acaba se entrepondo nesse contexto de forma limitada, sem compreender as "determinações macroestruturais de sua inserção profissional" nesse campo (Yamamoto, 2012, p. 11), haja vista o processo histórico de uma profissão elitista e essencialmente instituída pela clínica individual.

No final da década de 1970 e início da de 1980, a Psicologia, mais especificamente a Psicologia Social, avançou na perspectiva de consolidar práticas em consonância com pautas coletivas que emergiam no momento de abertura política no Brasil, quando as reivindicações por uma sociedade mais justa, ética e comprometida com os direitos humanos se expandiam. Em seu interior, a Psicologia, como campo de saber, instituía-se pela contradição entre o fazer prioritariamente técnico individual e as práticas associadas às questões éticas e políticas de atuação. Com isso, impulsionava movimentos políticos e institucionais de profissionais engajados com 
a militância em prol de determinados grupos sociais. É o caso das mobilizações do Movimento Nacional da Luta Antimanicomial (MNLA) e do Movimento Nacional de Meninos e Meninas de Rua (MNMMR), nos anos 80 (S. M. G. Sousa \& Tavares, 2012).

O marco legal importante para emergência e ampliação dessa nova Psicologia, como um campo de saber implicado com as demandas e reivindicações sociais, é a promulgação da Constituição Federal (CF), em 1988, que garante direitos sociais universais e equitativos à população. A partir de então, a Psicologia aos poucos amplia suas possibilidades de atuação, se insere nas políticas públicas e assume um compromisso com a necessidade de se construir um projeto ético-político para a profissão (Yamamoto, 2012).

Embora nesse processo de inserção da Psicologia em campos de atuação com coletivos se observe a produção de reflexões críticas ao contexto sociopolítico, a dimensão de uma prática que efetivamente contribua para a emancipação e para a potencialização das comunidades ainda é um projeto em construção. Segundo Yamamoto e Oliveira (2010), a CF impulsionou um padrão de bem-estar social que direcionou o trabaIho dos psicólogos brasileiros para contextos coletivos. Isso ocorreu não especificamente a partir de uma concepção teórico-técnica de uma prática menos elitista e mais comprometida com a sociedade, mas principalmente pelas mudanças no mundo do trabalho e pelas possibilidades de empregabilidade e estabilidade.

Outros instrumentos legais que também inserem a Psicologia na defesa das pautas sociais são: a implementação do Sistema Único de Saúde (SUS), a partir da Lei n. 8.080, em 1990; o Estatuto da Criança e do Adolescente (ECA), em 1990; a Política Nacional de Saúde Mental, considerada a Lei da Reforma Psiquiátrica (Lei n. 10.216), no ano de 2001; a instituição da Rede de Atenção Psicossocial (Raps), em 2008; a implementação do Sistema Único de Assistência Social (Suas), em 2011; e a regulamentação do Sistema Nacional de Atendimento Socioeducativo (Lei n. 12.594), em 2012. Esses instrumentos - considerados como avanços na garantia de direitos aos cidadãos, por preverem a presença de psicólogos na oferta dos serviços à população acabam reforçando a necessidade de que a Psicologia, como profissão, mantenha um constante diálogo com as políticas sociais.

Nessa interface, cabe destacar a inserção da Psicologia na saúde coletiva como estratégia para a inclusão de uma dimensão política na profissão. É o que se constata em um trabalho de Yamamoto e Oliveira (2010, p. 16), em que se descreve o contexto de ampliação do campo de trabalho do psicólogo, a partir da implementação do SUS e da Reforma Psiquiátrica brasileira, e se enfatizam as reflexões produzidas na Academia a respeito da relevância social da profissão. No entanto, para esses autores, as discussões acadêmicas não conseguiram promover a elaboração de modelos de trabalho que pudessem contemplar essa nova configuração da profissão. Daí se gerou a manutenção de práticas tradicionais no contexto de atuação das políticas sociais. Somente a partir do ano de 2000 , as práticas e os modelos teóricos começam a refletir no trabalho do psicólogo, em razão, principalmente, das mudanças advindas da Reforma Psiquiátrica. Assim, a argumentação de Yamamoto e Oliveira (2010) define o contexto atual da Psicologia no diálogo com as políticas sociais, em que as técnicas tradicionais de uma Psicologia Clínica individual se mesclam com modelos da clínica ampliada, do matriciamento e da humanização.

Essa inserção da Psicologia nas políticas sociais, além de contribuir com a ampliação dos campos de atuação, fomentou na Academia novas pesquisas e estudos alinhados às necessidades de compreensão dos processos dialéticos de inclusão/exclusão e à análise das condições de pobreza e desigualdade social (Sawaia, 2010). Assim, o cenário atual é fértil para o fortalecimento da atuação de uma Psicologia que se mantenha crítica no diálogo com as políticas garantidoras de direitos sociais e que, ao extrapolar o espaço das clínicas individualizadas, se comprometa com a produção de pesquisas capazes de contribuir com a construção de uma sociedade menos desigual. Esse é, portanto, o desafio da Psicologia na contemporaneidade: manter-se vigilante para permanecer comprometida com a necessidade de construir um projeto ético-político, de investir na produção de resistência e de potencializar as forças inventivas dos coletivos (Macedo \& Dimenstein, 2009).

Depois dessa exposição, cabe ressaltar que a produção científica do PSSP da PUC Goiás, aqui analisada, em interface com as políticas sociais, foi norteada pelos seguintes critérios, preestabelecidos por A. L. F. Costa e Yamamoto (2016): políticas públicas/ sociais e cidadania; políticas setoriais e legislação; programas, serviços, unidades e instituições públicos; vulnerabilidade e risco social, e movimentos e controle social. Por sua vez, a análise temática - a partir do critério de programas, serviços, unidades e instituições públicos inclui estudos referentes ao mundo da educação, da 
saúde e do trabalho. Quanto ao critério de vulnerabilidade e risco, a análise permite a inclusão dos trabalhos selecionados que abordaram temas relacionados à infância, à adolescência, às mulheres e à população LGBTT+.

\section{A Psicologia em Diálogo com Programas, Serviços, Unidades e Instituições Públicos}

Políticas sociais para educação, saúde e trabaIho. No campo da educação, as dissertações e teses selecionadas para esta pesquisa abordam os mais diversos temas, tais como: a percepção de professores do ensino público sobre seu trabalho em escolas inclusivas (Guimarães, 2013); o significado do bullying para os docentes (Branquinho, 2012); as necessidades educacionais especiais (Barboza, 2001; Mendes, 2016); a sociabilidade violenta em jovens escolares (A. E. Ferreira, 2012); a representação social da violência nas escolas (J. O. Santos, 2013); a diversidade de gênero na escola (Nunes, 2015); as dimensões afetivas do bem-estar subjetivo dos trabalhadores da educação (Silva, 2009), entre outros.

Barboza (2001), Silva (2009) e Mendes (2016) evidenciam a resistência dos professores à política de inclusão, bem como as vivências de inclusão/exclusão dos alunos na interatividade da sala de aula, mas não discutem as premissas teóricas e filosóficas que estão na base dessas políticas. Silva (2009) aborda as dimensões afetivas das relações dos trabalhadores da educação, sem aprofundar a discussão sobre essas dimensões por meio das quais os trabalhadores efetivam a política no contexto escolar. Segundo Goulart e Alcântara (2016, p. 13), os limites e alcances das políticas públicas não dependem de seus autores nem da sua "formalização nominal", mas "das pessoas que dão vida [...] aos processos institucionais".

Em muitas das dissertações e teses, as discussões giram em torno das relações e da inclusão social do indivíduo nas empresas, com análises de suas condições de trabalho relacionadas à sua saúde. Este é o caso do estudo de Curado (2006) sobre o catador de papel para reciclagem, um trabalho informal nem sempre reconhecido pela sociedade.

Outro tema relacionado ao mundo do trabaIho é a saúde mental dos trabalhadores. Ao analisar o significado social da condição humana, Tavares (2007) sugere a transformação do modelo atual de atenção à saúde mental, com base na confrontação entre as diretrizes teóricas e as diretrizes políticas da Reforma Psiquiátrica em política de Estado. Há também estudos sobre gestão do trabalho, com discussões que se valem de teorias sobre o desenvolvimento do movimento ambientalista no mundo e no Brasil (Farias, 2006; A. Oliveira, 2007), bem como sobre a saúde e bem-estar dos trabalhadores (J. X. Santos, 2009). Tal como no campo da educação, há temas que envolvem as categorias de inclusão/exclusão social, como no caso dos cuidadores (L. A. B. Lima, 2014) e as vivências nas organizações públicas e privadas (Hernandes, 2003).

De alguma forma, os estudos sobre gestão do trabalho apontam para a necessidade de aprofundamento teórico-metodológico sobre aspectos sociais e políticos, o que demanda a convocação de empresários ao exercício da cidadania para a redução da pobreza, das desigualdades e exclusões sociais. Essas discussões apontam para o desenvolvimento de políticas sociais que envolvam a responsabilidade social de cada cidadão em relação às necessidades da população em geral, especialmente dos grupos de crianças, adolescentes, mulheres e de LGBTT+. É o que se verá a seguir.

\section{A vulnerabilidade e risco social no diálogo da Psicologia com as políticas sociais}

\section{Políticas Sociais para a Infância e a Psicologia}

A infância brasileira ganhou notoriedade social e acadêmica a partir da década de 1980 , tendo como tema de destaque o menino de rua. Uma série de eventos e situações trouxe a infância - e, em especial, a infância pobre - para o centro da discussão nacional. Cabe mencionar, por exemplo, a instituição do Ano Internacional da Criança, em 1979; a criação do Movimento Nacional de Meninos e Meninas de Rua (MNMMR), em 1985; a realização de Encontros Nacionais de Meninos e Meninas de Rua, em 1986 e 1989; a criação do Fórum Nacional dos Direitos da Criança e do Adolescente (Fórum DCA) em 1988; e as publicações sobre o tema. Entravam também em cena novos atores: "as organizações intergovernamentais (Unicef, OMS, Unesco, ONU), internacionais [...]e as ONGs nacionais", segundo Rosemberg (1995, p. 236). A partir daí surgem as condições políticas para a promulgação do Estatuto da Criança e do Adolescente (ECA) em 1990, com impacto imediato na difusão dos estudos e pesquisas sobre e com crianças. Para Botarelli (2008), essa nova proposta constitucional insere os grupos excluídos nas pautas das discussões políticas e acadêmicas e os transformam em alvo de 
ações dos diversos segmentos profissionais, como, por exemplo, os psicólogos.

Indiscutivelmente, após a aprovação de leis, estatutos e criação de políticas focalizadas em famílias, crianças e adolescentes há uma expansão dos espaços institucionais de atuação dos psicólogos, notadamente na assistência social (Yamamoto \& Oliveira, 2010). A produção científica do PPSP da PUC Goiás expressa essa tendência nacional. No período de 2001 a 2018, 12 trabalhos acadêmicos têm como temática a vulnerabilidade e o risco social da infância/criança e as políticas sociais. Sete deles discutem temas diretamente relacionados às condições de vida e de sociabilidade das crianças. É o caso de abandono e institucionalização (Orionte, 2004); de violência física (Bernardes, 2011; L. A. Costa, 2004); de violência sexual (Andrade, 2012; F. S. Faria, 2005); de trabalho/serviço doméstico (Jardim, 2005); de depoimentos na justiça (Pinheiro, 2018). Essas sete pesquisas têm em comum a tematização das dimensões de exclusão/inclusão social (Sawaia, 2010) que afetam a vida das crianças de classes populares brasileiras e que historicamente estão ausentes das investigações da Psicologia e de outras áreas do conhecimento. Dessa forma, esses estudos contribuem para a construção de um campo investigativo que focaliza a dimensão da exclusão/inclusão na vivência infantil.

Os programas e/ou políticas sociais para a área da infância são objeto de estudo para quatro pesquisadoras (M. L. Lima, 2009; E. R. Oliveira, 2017; M. L. M. Oliveira, 2005; Schuster, 2015). M. L. M. Oliveira (2005) aborda a Política Nacional do Bem-Estar do Menor e as suas implicações no Estado de Goiás. M. L. Lima (2009) analisa as sete Conferências Nacionais dos Direitos da Criança e do Adolescente ocorridas entre 1993 e 2007, com ênfase no debate sobre a redução da idade penal. Schuster (2015) trabalha com psicólogas que registram casos de violência contra crianças na Secretaria Municipal de Saúde de Goiânia. E. R. Oliveira (2017) investiga profissionais da área de Psicologia, encarregados do Serviço de Proteção Especializado a Famílias e Indivíduos (Paefi).

Merece destaque a pesquisa de M. L. Lima (2009), por discutir a recente aprovação do Sistema Nacional de Atendimento Socioeducativo (Sinase) em 2006, a realização do mapeamento nacional pela Secretaria Especial de Direitos Humanos (SEDH) do Sinase - em especial, do sistema fechado - e a tentativa de criação do Sistema de Informação para a Infância e Adolescência (Sipia). Outra dissertação aborda a produção acadêmica no período de 2010 a 2015 e os cursos brasileiros de Pós-Graduação em Psicologia sobre a violência contra crianças e adolescentes (Carmo, 2018).
Essas pesquisas, para além de investigarem os objetos de estudo a que se propuseram, também fizeram sugestões e proposições. Orionte (2004) chama a atenção das autoridades para ouvirem "verdadeiramente" as crianças, para empregarem verbas públicas em infraestrutura e na qualificação profissional daqueles que atuam com crianças em situação de vulnerabilidade social. L. A. Costa (2004) propõe ações de prevenção e atendimentos psicossociais a crianças e famílias. Schuster (2015) também alerta para a importância da capacitação dos profissionais que atuam nos serviços públicos com crianças, em especial as vítimas de violências. Pinheiro (2018) conclama magistrados, membros do Ministério Público, defensores públicos e advogados a cumprirem o estatuto de sujeito de direitos das crianças possuem, sobretudo judicializadas, de modo a enxergar a perpetração de injustiças e de promover a dignificação do tratamento a elas dispensado.

Enfim, essas investigações científicas contribuem no campo da assistência, da saúde e da justiça que têm a criança como sujeito prioritário de atenção e reafirmam a compreensão política de que "o trabalho na proteção social básica exige dos psicólogos não apenas uma adequação do trabalho; exige um conhecimento de aspectos que estão fora do escopo do que a psicologia delimitou em seus campos de saber" (Yamamoto \& Oliveira, 2010, p. 21).

\section{A Psicologia em Diálogo com Políticas Sociais para a Adolescência}

$\mathrm{Na}$ atualidade, a adolescência tem sido concebida com base em diversas perspectivas, dependendo das abordagens teóricas em que se ancoram os estudos. Caracterizada por uma pluralidade, a adolescência se constitui fundamentalmente em uma categoria relacionada à cultura e aos contextos históricos, sociais e econômicos em que se insere. Portanto, ao ser abordada como uma temática de estudo da Psicologia, é fundamental superar a visão meramente biológica e naturalista da fase. Assim, na análise das políticas sociais, deve-se considerar em que medida as ações podem possibilitar as diversas expressões da adolescência, bem como em que dimensão o direito de se desenvolver biopsicossocialmente de forma plena tem sido garantido ao adolescente brasileiro. Nesse sentido, paulatinamente, os estudos da Psicologia têm superado a visão determinista de considerar a adolescência como uma fase natural de conflitos e têm também contemplado análises que agregam a complexa dimensão da condição de ser adolescente na sociedade contemporânea, buscando demarcar as adolescências como construção histórico-social. 
Os trabalhos de mestrado e doutorado da PUC Goiás que abordam a temática da adolescência e a interface com as políticas sociais possibilitam a demarcação de momentos importantes de transformação da realidade, dos marcos legais que asseguram novas perspectivas para essa população, bem como de uma análise das condições históricas e sociais excludentes das adolescências no Brasil. Essas compreensões reforçam a gradativa superação da leitura individual e descontextualizada que a Psicologia historicamente tem desenvolvido sobre a adolescência, assinalando, mesmo que ainda timidamente, um diálogo com as políticas sociais destinadas a esse grupo. Convém ressaltar que esse diálogo é quase sempre tangenciado, com exceção daqueles estudos relacionados à temática do adolescente que comete infrações. Nestes, há uma discussão consistente do lugar que cabe ao adolescente infrator na sociedade e uma crítica à atenção que lhe é dada pelas políticas públicas. Esses estudos ratificam os marcos legais que proporcionam ao adolescente autor de ato infracional possibilidades de mudanças no que se refere ao seu destino. Temas como medidas socioeducativas (Cabral, 2003; Lobo, 2011; Rocha, 2010; Tavares 2014) e desinstitucionalização do adolescente (Tavares, 2014) perpassam questões como a política de responsabilização do adolescente autor de ato infracional, os direitos do adolescente, os direitos humanos e as políticas sociais de educação e saúde.

Nos trabalhos analisados há uma compreensão dos avanços do Sistema de Garantia de Direitos das Crianças e Adolescentes como "ferramenta estratégica de alcance dos direitos fundamentais de crianças e adolescentes" (Lobo, 2011), bem como o reconhecimento da ausência de políticas efetivas de socialização e de integração das famílias na socioeducação dos adolescentes pobres que cometem infrações.

Cabe reafirmar que a análise dos trabalhos selecionados possibilitou apreender que a abordagem da Psicologia Sócio-Histórica é a que faz maior interface com as políticas sociais direcionadas ao público adolescente, talvez devido ao fato de os temas enfocados nessa abordagem exigirem uma reflexão alinhada às dimensões políticas e históricas do contexto brasileiro e do lugar que cabe ao adolescente na sociedade contemporânea. Apesar de a interface com as políticas públicas estar contemplada na maioria dos estudos analisados, essa discussão ainda é monotemática, já que, como se afirmou anteriormente, se referem ao cometimento de atos infracionais por adolescentes. Os demais trabalhos desenvolvem uma análise sobre a adolescência, em que se realçam aspectos mais subjetivos, como ideação suicida (A. C. G. M. Faria, 2014), gravidez na adolescência (Alves, 2013) e violência sexual (Freire, 2010; Melo, 2008).

Desse modo, o posicionamento da Psicologia, em constante interlocução com as políticas sociais, demarca uma mudança na perspectiva histórica da produção científica: a substituição da visão psicologizante e individualista de temas amplos e multifatoriais por uma visão crítica, contextualizada e instituída histórica, política e socialmente.

\section{O Diálogo da Psicologia com Políticas Sociais para Mulheres e População LGBTT+}

O período conhecido por redemocratização do Brasil foi considerado como um marco para o surgimento das políticas sociais. Nesse novo cenário, os movimentos sociais que antes estavam imobilizados pelos efeitos do regime ditatorial voltaram a intensificar as lutas por direitos civis, principalmente por ações dirigidas aos grupos sociais considerados mais vulneráveis. Daí, o movimento feminista e o LGBTT+ se inseriram no cotidiano dos partidos, dos governos e principalmente das organizações não governamentais, promovendo a discussão da transversalidade de gênero e das sexualidades no contexto das políticas sociais (Borges, 2012).

Por reconhecer a importância de inserir os diversos marcadores sociais que produzem as desigualdades sociais (classe, gênero, raça, sexualidade, entre outros) nas análises feitas no decorrer deste trabalho, focalizam-se então as dissertações e teses voltadas para o tema. Em suas dissertações, Suassuna (2011), M. P. D. Sousa (2013) e Gama (2014) tiveram como objeto de estudos as mulheres. Os dois primeiros estudos enfocaram a violência contra as mulheres, adotando como referencial teórico a Psicologia SócioHistórica, de Vigotsky (2004); o terceiro abordou o envelhecimento feminino, com base na perspectiva cultural histórica de González-Rey (2003). Já em sua tese de doutorado, Andrade (2017) analisou a violência contra a população trans (travestis e transexuais), sob a perspectiva da Psicologia Socioconstrucionista e das teorias feministas (Nogueira, 2001; Spink, 2000).

Todas as quatro pesquisas situaram historicamente a emergência das políticas sociais como forma de reconhecimento da violência na vida das mulheres e do grupo LGBTT+. A discussão sobre a violência contra as mulheres (M. P. D. Sousa, 2013; Suassuna, 2011) incorpora o conceito de gênero a partir de Chaui, Scott, Saffioti e Gregory, assinalando que o fenômeno 
da violência deve ser entendido no aspecto relacional e na dimensão das assimetrias de poder entre homens e mulheres. Já no caso dos LGBTT+, a discussão é sustentada a partir da categoria "interseccionalidade" (Nogueira, 2013), que parte do pressuposto de que a violência motivada por gênero e orientação sexual requer uma análise que alcance a intersecção de eixos diversos de subordinação na produção de condições desiguais de existência.

\section{Considerações finais}

Ao tentar reconstruir pari passu o percurso deste artigo - numa tentativa de responder aos nossos questionamentos iniciais -, constatamos que nossos achados empíricos identificaram que das 484 dissertações (421) e teses (63) do Programa de Pós-Graduação em Psicologia da PUC Goiás, 39 (8\%) tinham como objeto e/ou tema de estudo as políticas sociais. Resultados semelhantes foram encontrados por A. L. F. Costa (2014), em sua pesquisa acerca de teses acadêmicas de Programas de Pós-Graduação em Psicologia, no Brasil, no período de 2007 a 2009. Essa autora constatou que, das 824 teses defendidas, 105 $(12,7 \%)$ eram pesquisas que versavam sobre as "políticas sociais". Também Féres-Carneiro, Bastos, Feitosa, Seidl-deMoura e Yamamoto (2010) identificaram que a temática das "políticas públicas" está presente em somente 6,2\% das linhas de pesquisa ativas da Pós-Graduação em Psicologia no país, o que faz com que essa temática figure em $18^{\circ}$ lugar em termos de produção acadêmica.

A análise das teses e dissertações a partir dos critérios estabelecidos por A. L. F. Costa e Yamamoto (2016) evidencia que a discussão relativa às políticas sociais na Psicologia ainda é tímida, uma vez que muitos dos trabalhos que focaram na temática da vulnerabilidade e risco social apresentaram uma discussão mais centralizada na população atendida e não contemplando muitas vezes uma análise do contexto macrossocial determinante dessas condições. Por sua vez, os estudos analisados, segundo o critério temático dos programas, serviços, unidades e instituições públicos, em sua totalidade, referiram-se aos espaços de atuação da Psicologia, sem abordar as políticas sociais como tema central.

Não ignoramos que essas 39 pesquisas desenvolvidas com base em temáticas que demandam a criação, ou a manutenção, de políticas sociais certamente trouxeram contribuições expressivas para os problemas tratados, especialmente na formação de pesquisadores que atuam no setor público e se tornam responsáveis por desenvolver e/ou executar as referidas políticas. Afinal, esse universo de pesquisa é ainda reduzido, o que talvez expresse o "não lugar" de temas com grande impacto social na produção acadêmico da Psicologia.

Embora saibamos das expressivas contribuições do Programa de Pós-Graduação em Psicologia da PUC Goiás, fazemos coro às reflexões de A. L. F. Costa (2014) quando aponta o paradoxo entre a ampla inserção do profissional de Psicologia nas ditas "áreas sociais" e a reduzida/pouca produção acadêmica sobre políticas sociais no Brasil. A. L. F. Costa (2014) alerta ainda para a necessidade de que a ciência psicológica, caso queira contribuir efetivamente para o desenvolvimento da sociedade, faça a articulação entre os pesquisadores da área, aprofunde o debate teórico e organize os conhecimentos disponíveis em prol da construção de políticas sociais.

Ao final desta exposição, consideramos que a análise descritiva e exploratória dos resumos de dissertações e teses defendidas na PUC Goiás, no período de 2001 a 2018, contribui para a expansão e interiorização da Pós-Graduação em Psicologia no país, bem como para a difusão de pesquisas sobre políticas sociais. Entretanto, tal constatação não está isenta de desafios.

\section{Referências}

Alves, J. C. (2013) Dimensões subjetivas de mães adolescentes em contexto de vulnerabilidade social (Dissertação de Mestrado, Pontifícia Universidade Católica de Goiás, Goiás). Recuperado de http://tede2.pucgoias.edu.br:8080/handle/tede/1826

Andrade, V. N. G. (2012). As falas dos atendentes do Disque 100 sobre a escuta das denúncias de abuso sexual contra crianças e adolescentes (Dissertação de Mestrado, Pontifícia Universidade Católica de Goiás, Goiás). Recuperado de http://tede2.pucgoias.edu.br:8080/handle/ tede/1804

Andrade, V. N. G. (2017). Transfobia no percurso denunciativo brasileiro: um estudo a partir do Disque Direitos Humanos da Presidência da República (Tese de Doutorado, Pontifícia Universidade Católica de Goiás, Goiás). Recuperado de http://tede2.pucgoias.edu.br:8080/handle/tede/3949

Barboza, S. F. (2001). Incluindo a professora: subjetividade no contexto da inserção de crianças com necessidades educacionais especiais em classes comuns de ensino (Dissertação de Mestrado, Pontifícia Universidade Católica de Goiás, Goiás). Recuperado de http://tede2. pucgoias.edu.br:8080/handle/tede/3973

Bastos, A. V. B., \& Godim, S. M. G. (2010). O trabalho do psicólogo no Brasil. Porto Alegre: Artmed.

Bernardes, L. F. (2011). Violência física intrafamiliar contra crianças: os sentidos atribuídos por três gerações (Dissertação de Mestrado, Pontifícia Universidade Católica de Goiás, Goiás). Recuperado de http://tede2.pucgoias.edu.br:8080/handle/tede/3575

Borges, L. S. (2012). Políticas públicas, movimento LGBT e a Psicologia: diálogos e tensões de um campo em construção. In J. C. Chaves (Org.), Psicologia social e políticas públicas: contribuições e controvérsias (pp. 147-158). Goiânia: Editora da PUC Goiás.

Botarelli, A. (2008). O psicólogo nas políticas de proteção social: uma análise dos sentidos e da práxi (Tese de Doutorado, Pontifícia Universidade Católica de São Paulo, São Paulo). Recuperado de https://tede2.pucsp.br/handle/handle/17265 
Branquinho, S. C. (2012). Bullying: os significados para os docentes do ensino fundamental das escolas públicas municipais da cidade de Rio Verde, Goiás (Dissertação de Mestrado, Pontifícia Universidade Católica de Goiás, Goiás). Recuperado de http://tede2.pucgoias. edu.br:8080/handle/tede/1794

Cabral, S. H. (2003). Adolescentes em liberdade assistida: uma análise psicossocial (Dissertação de Mestrado, Pontifícia Universidade Católica de Goiás, Goiás). Recuperado de http://tede2.pucgoias. edu.br:8080/handle/tede/1940

Carmo, L. M. (2018). A violência contra crianças e adolescentes nas dissertações e teses brasileiras em Psicologia (de 2010 a 2015) (Dissertação de Mestrado, Pontifícia Universidade Católica de Goiás, Goiás). Recuperado de http://tede2.pucgoias.edu.br:8080/handle/ tede/3987

Costa, A. L. F. (2014). A produção científica de psicologia e o debate sobre política social. (Tese de Doutorado, Universidade Federal do Rio Grande do Norte, Natal). Recuperado de https://repositorio.ufrn. br/jspui/handle/123456789/19635

Costa, A. L. F., \& Yamamoto, O. H. (2016). Políticas sociais na Pós-Graduação Stricto Sensu de Psicologia. Estudos de Psicologia, 21(4), 456-467. doi: 10.5935/1678-4669.20160044

Costa, L. A. (2004). Infância e violência física intrafamiliar: os significados e sentidos para crianças vítimas (Dissertação de Mestrado, Pontifícia Universidade Católica de Goiás, Goiás). Recuperado de http://tede2. pucgoias.edu.br:8080/handle/tede/1929

Curado, L. F. R. M. (2006). Uma análise psicossocial das relações de trabalho dos catadores de material reciclável organizados em cooperativas de reciclagem (Dissertação de Mestrado, Pontifícia Universidade Católica de Goiás, Goiás). Recuperado de http://tede2. pucgoias.edu.br:8080/handle/tede/1879

Faria, A. C. G. M. (2014). Suicídio na adolescência (Dissertação de Mestrado, Pontifícia Universidade Católica de Goiás, Goiás). Recuperado de http://tede2.pucgoias.edu.br:8080/handle/tede/1831

Faria, F. S. (2005). Violência sexual familiar: significados da experiência vivida por duas crianças de 7 anos (Dissertação de Mestrado, Pontifícia Universidade Católica de Goiás, Goiás). Recuperado de http://tede2.pucgoias.edu.br:8080/handle/tede/1846

Farias, K. M.O. (2006). Os impactos dos programas de gestão ambiental nos trabalhadores e nos processos da organização (Dissertação de Mestrado não publicada). Pontifícia Universidade Católica de Goiás, Goiás.

Féres-Carneiro, T.; Bastos, A. V., Feitosa, M. A. G., Seidl-de-Moura, M. L., \&Yamamoto, O.H. (2010). Lacunas, metas e condições para a expansão da pós-graduação em psicologia no país. Psicologia:Reflexão e Crítica, 23(suplemento), 11-24. doi: 10.1590/S0102-79722010000400003

Ferreira, A. E. (2012). Função paterna e sociabilidade violenta em jovens escolares (Tese de Doutorado, Pontifícia Universidade Católica de Goiás, Goiás). Recuperado de http://tede2.pucgoias.edu.br:8080/ handle/tede/1752

Ferreira, N. S. A. (2002). As pesquisas denominadas "estado da arte". Educação \& Sociedade, 23(79), 257-272. doi: 10.1590/ S0101-73302002000300013

Freire, A. L. S. (2010). Constituição do sujeito sob o signo da violência: estudo de um caso (Dissertação de Mestrado, Pontifícia Universidade Católica de Goiás, Goiás). Recuperado de http://tede2.pucgoias. edu.br:8080/handle/tede/1777

Gama, W. (2014). Companhia Senhoras do Cerrado: subjetividade e saúde no processo de envelhecer (Dissertação de Mestrado, Pontifícia Universidade Católica de Goiás, Goiás). Recuperado de http://tede2.pucgoias.edu.br:8080/handle/tede/1823

Gonzalez-Rey, F. L. (2003). Sujeito e subjetividade: uma aproximação histórico-cultural. São Paulo: Thomson Learning.

Goulart, D. M., \& Alcântara, R. (2016). Explosão medicalizante e implosão pedagógica: desafios e alternativas no contexto escolar. In D. M.
Goulart \& R. Alcântara. (Orgs.), Educação escolar e subjetividade: desafios contemporâneos (pp. 13-49). Rockville: Global South Press.

Guimarães, L. C. (2013). A percepção de professores do ensino público sobre seu trabalho em escolas inclusivas (Dissertação de Mestrado não publicada). Pontifícia Universidade Católica de Goiás, Goiás.

Hernandes, J. C. (2003). Vivências de prazer e sofrimento: um estudo exploratório com trabalhadores de um hotel de Goiânia (Dissertação de Mestrado não publicada). Pontifícia Universidade Católica de Goiás, Goiás.

Jardim, D. M. (2005). O serviço doméstico e as brincadeiras no processo de socialização de crianças pertencentes às camadas populares (Dissertação de Mestrado, Pontifícia Universidade Católica de Goiás, Goiás). Recuperado de http://tede2.pucgoias.edu.br:8080/handle/ tede/2003

Lima, L. A. B. (2014). Residências terapêuticas no município de Jataí: com a palavra, os cuidadores em saúde (Dissertação de Mestrado, Pontifícia Universidade Católica de Goiás, Goiás). Recuperado de http://tede2.pucgoias.edu.br:8080/handle/tede/1870

Lima, M. L. (2009). Conferências nacionais dos direitos da criança e do adolescente: Os significados da redução da idade penal (Dissertação de Mestrado, Pontifícia Universidade Católica de Goiás, Goiás) Recuperado de http://tede2.pucgoias.edu.br:8080/handle/tede/2017

Lobo, V. J. (2011). Considerações dos atores do sistema de garantia de direitos sobre o processo de execução da medida socioeducativa de privação de liberdade (Dissertação de Mestrado, Pontifícia Universidade Católica de Goiás, Goiás). Recuperado de http://tede2. pucgoias.edu.br:8080/handle/tede/2054

Macedo, J., \& Dimenstein, M. (2009). Psicologia e a produção do cuidado no campo do bem-estar social. Psicologia \& Sociedade, 21(3), 293300. doi: 10.1590/S0102-71822009000300002

Melo, G. A. (2008). O adolescente autor de violência sexual: estudo psicossocial (Dissertação de Mestrado, Pontifícia Universidade Católica de Goiás, Goiás). Recuperado de http://tede2.pucgoias. edu.br:8080/handle/tede/2016

Mendes, C. B. Q. (2016). Práticas inclusivas e representações sociais do aluno com deficiência intelectual (DI) (Dissertação de Mestrado, Pontifícia Universidade Católica de Goiás, Goiás). Recuperado de http://tede2.pucgoias.edu.br:8080/handle/tede/3697

Nogueira, C. (2001). Construcionismo social, discurso e género. Psicologia, 15(1), 43-65. Recuperado de http://www.scielo.mec.pt scielo.php?script=sci_arttext\&pid=S0874-20492001000100003\&lng= pt\&tIng=pt

Nogueira, C. (2013). A teoria da interseccionalidade nos estudos de gênero e sexualidades: condições de produção de "novas possibilidades" no projeto de uma psicologia feminista crítica. In A. L. C. Brizola, A. V. Zanella, \& M. Gesser (Orgs.), Práticas sociais, políticas públicas e direitos humanos (pp. 227-248). Florianópolis: ABRAPSO-NUPPE/ $\mathrm{CFH} / \mathrm{UFSC}$.

Nunes, E. M. (2015). Gênero e diversidade na escola: limites e possibilidades na formação de professores (as) (Dissertação de Mestrado, Pontifícia Universidade Católica de Goiás, Goiás). Recuperado de http://tede2.pucgoias.edu.br:8080/handle/tede/1884

Oliveira, A. (2007). A gestão ambiental entre o discurso legitimador e práticas instrumentais (Dissertação de Mestrado, Pontifícia Universidade Católica de Goiás, Goiás). Recuperado de http://tede2. pucgoias.edu.br:8080/handle/tede/1967

Oliveira, E. R. (2017). Os significados do atendimento psicossocial realizado por psicólogos dos CREAS de Goiânia às crianças vítimas de abuso sexual (Dissertação de Mestrado, Pontifícia Universidade Católica de Goiás, Goiás). Recuperado de http://tede2.pucgoias.edu.br:8080/ handle/tede/3733

Oliveira, M. L. M. (2005). Aldeia Juvenil: duas décadas de contraposição à cultura da institucionalização de crianças e adolescentes pobres em Goiás (Dissertação de Mestrado, Pontifícia Universidade Católica 
Psicologia e políticas sociais: as contribuições de um programa de pós-graduação em Psicologia

de Goiás, Goiás). Recuperado de http://tede2.pucgoias.edu.br:8080/ handle/tede/1894

Orionte, I. (2004). Abandono e institucionalização de crianças significados e sentidos (Dissertação de Mestrado, Pontifícia Universidade Católica de Goiás, Goiás). Recuperado de http://tede2.pucgoias.edu.br:8080/ handle/tede/1889

Pinheiro, J. C. (2018). A escuta das crianças em juízo: uma análise dos significados atribuídos pelos profissionais do direito à luz da Psicologia Sócio-Histórica (Dissertação de Mestrado, Pontifícia Universidade Católica de Goiás, Goiás). Recuperado de http://tede2.pucgoias. edu.br:8080/handle/tede/3963

Rocha, T. T. (2010). O olhar materno diante da medida socioeducativa de privação de liberdade em Goiás (Dissertação de Mestrado não publicada). Pontifícia Universidade Católica de Goiás, Goiás.

Rosemberg, F. (1996). Estimativas sobre crianças e adolescentes em situação de rua: procedimentos de uma pesquisa. Psicologia: Reflexão e Crítica, 9(1), 21-58.

Santos, J. O. (2013). A representação social da violência nas escolas $e$ as incivilidades em professores de Cuiabá (Tese de Doutorado não publicada). Pontifícia Universidade Católica de Goiás, Goiás.

Santos, J.X. (2009). Análise psicossocial do bem-estar de trabalhadores de um centro de reabilitação de Goiânia (Dissertação de Mestrado, Pontifícia Universidade Católica de Goiás, Goiás). Recuperado de http://tede2.pucgoias.edu.br:8080/handle/tede/2025

Sawaia, B. B. (2010) O sofrimento ético-político como categoria de análise da dialética exclusão/inclusão social. In B. B. Sawaia (Org.), As artimanhas de exclusão: análise psicossocial e ética da desigualdade social (pp. 97-118). Petrópolis, RJ: Vozes.

Schuster, L. (2015). Repertórios e sentidos sobre a notificação compulsória de casos de violência contra crianças e adolescentes no município de Goiânia - Goiás. (Dissertação de Mestrado, Pontifícia Universidade Católica de Goiás, Goiás). Recuperado de http://tede2.pucgoias. edu.br:8080/handle/tede/1886

Silva, E. N. (2009). Coping e dimensões afetivas do bem-estar subjetivo: um estudo com trabalhadores da educação (Dissertação de Mestrado, Pontifícia Universidade Católica de Goiás, Goiás). Recuperado de http://tede2.pucgoias.edu.br:8080/bitstream/tede/2012/1/Eliete\%20 Neves\%20da\%20Silva.pdf
Sousa, M. P. D. (2013). Os sentidos de violência para mulheres afetivamente envolvidas com autores de violência sexual contra crianças e adolescentes (Dissertação de Mestrado, Pontifícia Universidade Católica de Goiás, Goiás). Recuperado de http://tede2. pucgoias.edu.br:8080/handle/tede/1819

Sousa, S. M.G., \& Tavares, R.C. (2012). As contribuições da Psicologia SócioHistórica para as políticas públicas da área da infância, adolescência e juventude. In J. C. Chaves (Org.), Psicologia Social e políticas públicas: contribuições e controvérsias. Goiânia: Editora da PUC Goiás.

Spink, M. J. (2000). Práticas discursivas e produção de sentidos no cotidiano. São Paulo: Centro Edelstein de Pesquisas Sociais. [Edição Virtual].

Suassuna, M. (2011). Mulheres em situação de violência conjugal: relações afetivas (Dissertação de Mestrado, Pontifícia Universidade Católica de Goiás, Goiás). Recuperado de http://tede2.pucgoias. edu.br:8080/handle/tede/1785

Tavares, R. C. (2007). A reforma psiquiátrica e relações de poder: significados apreendidos entre os trabalhadores do Centro de Atenção Psicossocial (CAPS) em Goiânia (Dissertação de Mestrado não publicada). Pontifícia Universidade Católica de Goiás, Goiás.

Tavares, R.C.(2014). “Eu já perdi muita coisa, minha familia principalmente”. um estudo psicossocial sobre duas políticas de desinstitucionalização do adolescente (Tese de Doutorado, Pontifícia Universidade Católica de Goiás, Goiás). Recuperado de http://tede2.pucgoias.edu.br:8080/ handle/tede/1762

Vigotsky, L. S. (2004). Teoria e método em Psicologia (3ª ed., C. Berliner, Trad.). São Paulo: Martins Fontes, 2004.

Yamamoto, O.H. (2012). 50 anos de profissão: responsabilidade social ou projeto ético-político?. Psicologia: Ciência e Profissão, 32(spe), 6-17. doi: 10.1590/S1414-98932012000500002

Yamamoto, O. H., \& Oliveira, I. F. (2010). Política social e Psicologia: uma trajetória de 25 anos. Psicologia: Teoria e Pesquisa, 26, 9-24. doi: 10.1590/ S0102-37722010000500002

Zanella, A. V., \& Titon, A. P. (2005). Análise da produção científica sobre criatividade em programas de brasileiros de pós-graduação em psicologia (1994-2001). Psicologia em Estudo, 10(2), 305-316. doi: 10.1590/S1413-73722005000200018

Lenise Santana Borges, Doutora em Psicologia Social pela Pontifícia Universidade Católica de São Paulo - PUC/SP, é Professora da Pontifícia Universidade Católica de Goiás - PUC/ Goiás. Endereço para correspondência: Rua 4, n.60, apto 1902, Setor Oeste, Goiânia-GO, CEP 74.110-140. Telefone: (62) 9815-9139. Email: esinel@uol.com.br

Rosana Carneiro Tavares, Doutora em Psicologia pela Pontifícia Universidade Católica de Goiás - PUC/Goiás, é Professora da Pontifícia Universidade Católica de Goiás (PUC Goiás). Email: rosana.carneirotavares@gmail.com

Sonia M. Gomes Sousa, Doutora em Psicologia Social pela Pontifícia Universidade Católica de São Paulo - PUC/SP, é Pró-Reitora de Graduação da Pontifícia Universidade Católica de Goiás - PUC/Goiás. Email: smgsousa2@gmail.com

Vannúzia Leal Andrade Peres, Doutora em Psicologia e Pós Doutora em Educação pela Universidade de Brasília - UnB, é Professora da Pontifícia Universidade Católica de Goiás - PUC-Goiás. Email: vannuzia@terra.com.br

Recebido em 28.mai.19 Revisado em 05.nov.19 Aceito em 31.dez.19 